\title{
THE EXERCISE ELECTROCARDIOGRAM IN PATIENTS WITH CARDIAC PAIN
}

\author{
BY \\ H. G. LLOYD-THOMAS \\ From the Cardiac Department, the London Hospital \\ Received January 25, 1961
}

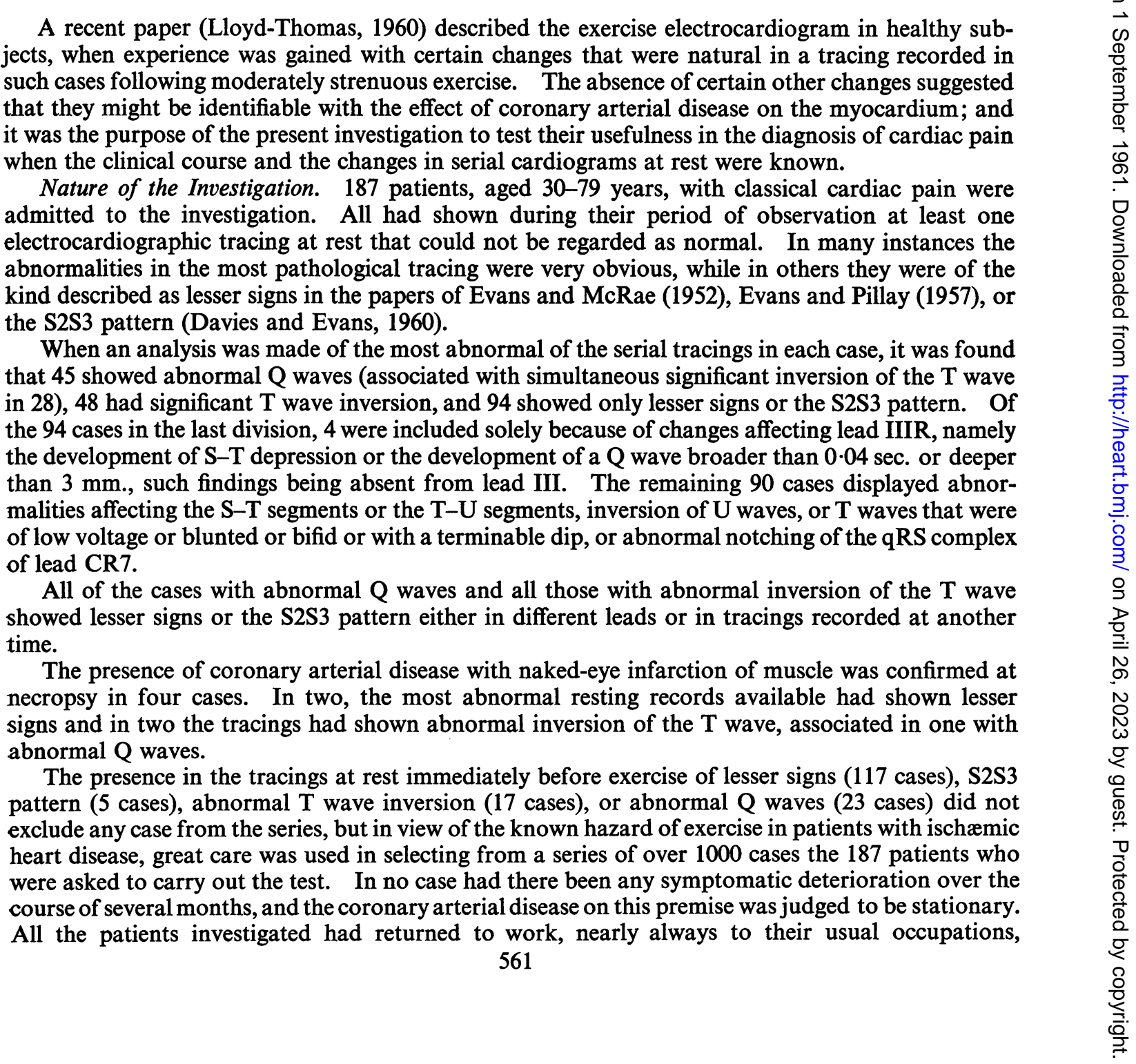


several months or years before the test, and no case was accepted for this investigation if it was considered that the amount of effort involved in the test exceeded that readily tolerated by the patient in his usual everyday activities.

Observations extending over the course of nine years were available in 13 patients, over eight years in 4 , over seven years in 18 , over six years in 15 , over five years in 20 , over four years in 11 , over three years in 18 , over two years in 20 , over $12-24$ months in 21 , and over 3-12 months in 47 patients.

All the records were taken with the patient in the semi-recumbent posture. Normal standardization was used throughout and the records taken with a three-channel Elmqvist electrocardiograph. The leads used were the three standard limb leads, lead IIIR (lead III recorded on inspiration), and the chest leads CR1, CR4, and CR7. CR leads were preferred to V leads because they depicted more clearly the lesser signs of coronary arterial disease. Tracings were taken before exercise and at intervals of two, four, and ten minutes after completion of the exercise. In each instance the same seven leads were recorded. Both the rate of exercise and the total amount of effort used in this investigation were similar to that used in the group of normal subjects previously reported.

\section{Cardiographic Patterns Following Exercise}

Following the results of a detailed analysis of the effects of exercise in healthy subjects (LloydThomas, 1961), the tracings from the present group were analysed for deviations of the point $J$, alterations in the form of the S-T segments to show a plane or sagging contour, the development of inversion or flattening of a previously upright $T$ wave, inversion of a previously flat or upright $U$ wave, and a considerable reduction of the voltage of the $\mathbf{R}$ wave in lead CR4. Attention was also paid to the incidence of tall $T$ waves, elevation of the $S-T$ segment, and to the onset of intraventricular conduction defects, ectopic beats, or other arrhythmias. Because lead III had previously been found to be unreliable in the exercise test, alterations in the $S-T$ segment and in the $T$ wave confined to this lead were ignored. The incidence of these patterns in the tracings recorded after exercise is summarized in Table I.

TABLE I

The Incidence of Certain Patterns after Exercise in 187 Patients with Classical Cardiac Pain

\begin{tabular}{|c|c|c|c|c|}
\hline \multicolumn{3}{|l|}{ Pattern } & No. of & Associated changes* \\
\hline $\begin{array}{l}\text { 1. Depression of } J \text { by } 1 \mathrm{~mm} \text {. or more } \\
\text { 2. Plane or sagging } \mathrm{S}-\mathrm{T} \text { segment } \\
\text { 3. T wave becomes flat or inverted } \\
\text { 4. Inverted T becomes upright (lead } \\
\text { 5. Tall T waves develop } \\
\text { 6. T-U segment becomes depressed b } \\
\text { 7. U wave becomes inverted } \ldots \\
\text { 8. Marked decrease of } R \text { wave in lea } \\
\text { 9. Elevation of } S-T \text { segment } \ldots \\
\text { 10. Ectopic beats . } \\
\text { 11. Ventricular fibrillation } \\
\text { 12. Intraventricular conduction delay } \\
\text { 13. None of patterns } 1 \text { to } 12\end{array}$ & $\begin{array}{l}\text { below the P-C } \\
\ldots \\
\text { III excluded) } \\
\text { below the P-R } \\
\begin{array}{ll}\text { d } & \ldots \\
\text { CR4 } & \ldots \\
\ldots & \ldots \\
\ldots & \ldots \\
\ldots & \ldots \\
\ldots & \ldots \\
\ldots & \ldots\end{array}\end{array}$ & 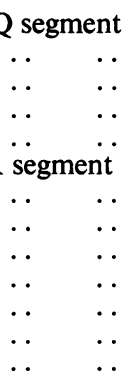 & $\begin{array}{r}126 \\
155 \\
14 \\
6 \\
4 \\
8 \\
4 \\
8 \\
6 \\
21 \\
1 \\
0 \\
19\end{array}$ & $\begin{array}{l}117 \mathrm{~S}-\mathrm{T} \\
117 J \\
9 \mathrm{~S}-\mathrm{T} \text { and } J, 4 \mathrm{~S}-\mathrm{T} \\
4 \mathrm{~S}-\mathrm{T} \\
3 \mathrm{~S}-\mathrm{T} \text { and } J, 2 \mathrm{~S}-\mathrm{T} \\
2 \mathrm{~S}-\mathrm{T} \text { and } J, 2 \mathrm{~S}-\mathrm{T} \text {, one } J \\
4 \mathrm{~S}-\mathrm{T} \text { and } J \\
\mathrm{~S}-\mathrm{T} \text { and } J \text { in } 7 \\
\mathrm{~S}-\mathrm{T} \text { and } J \text { in } 5, \mathrm{~S}-\mathrm{T} \text { in one } \\
\mathrm{S}-\mathrm{T} \text { and } J \text { in } 13, \mathrm{~S}-\mathrm{T} \text { in } 5, \mathrm{~J} \text { in } 2 \\
-\end{array}$ \\
\hline
\end{tabular}

* S-T = plane or sagging S-T segment. $\quad J=$ depression of $J$ by $1 \mathrm{~mm}$. or more below the P-Q segment.

Depression of the $J$ to $1 \mathrm{~mm}$. or more below the $\mathrm{P}-\mathrm{Q}$ segment developed in 126 cases. The $\mathrm{S}-\mathrm{T}$ segment showed a plane (i.e. a segment that is flat for $0.1 \mathrm{sec}$. or longer) or sagging deformity (i.e. a segment in which there is a decline from $J$ at some interval during its course) in 155 cases. The $T$ wave became flat or inverted in 14 , an inverted $T$ wave became upright (lead III excluded) in 6 , 
and tall $\mathrm{T}$ waves developed in 4 cases. The T-U segment became depressed below the $\mathrm{P}-\mathrm{Q}$ segment in 8 and the $U$ wave became inverted in 4 cases. The voltage of the $R$ wave in lead CR4 decreased to below 60 per cent of its resting voltage in 8 cases. Elevation of the S-T segment exceeding $1 \mathrm{~mm}$. developed in 6 cases. Ectopic beats were recorded in 21 cases. The addition of bundle-branch block was not observed in any case. One patient developed transient ventricular fibrillation (Fig. 16). None of the above patterns were observed in 19 cases.

\section{The S-T Segment After Exercise}

In our recent series of normal subjects, none of whom showed an $R$ wave in excess of $20 \mathrm{~mm}$., depression of the $J$ by $1.0 \mathrm{~mm}$. or more below the $\mathrm{P}-\mathrm{Q}$ segment after exercise was not seen. In the present series of 187 patients with cardiac pain, the $J$ became depressed by $1.0 \mathrm{~mm}$. or more below the $\mathrm{P}-\mathrm{Q}$ segment in 126 cases. The maximum depression amounted to $4 \mathrm{~mm}$. in 6 patients, $3 \mathrm{~mm}$. in $10,2 \mathrm{~mm}$. in 46, $1 \mathrm{~mm}$. in 64, and less than $1 \mathrm{~mm}$. in 61 patients. Depression of the $J$ amounting to $1 \mathrm{~mm}$. or more thus occurred in $126(67 \%)$ and to less than $1 \mathrm{~mm}$. in 61 cases $(33 \%)$. There were 88 patients in whom a total of 160 leads abnormal at rest failed to show a $1 \mathrm{~mm}$. depression of the $J$.

Depression of the $J$ when it occurred was always maximal in the record taken at two minutes following cessation of exercise, and in no patient did such depression show an increase in the later records.

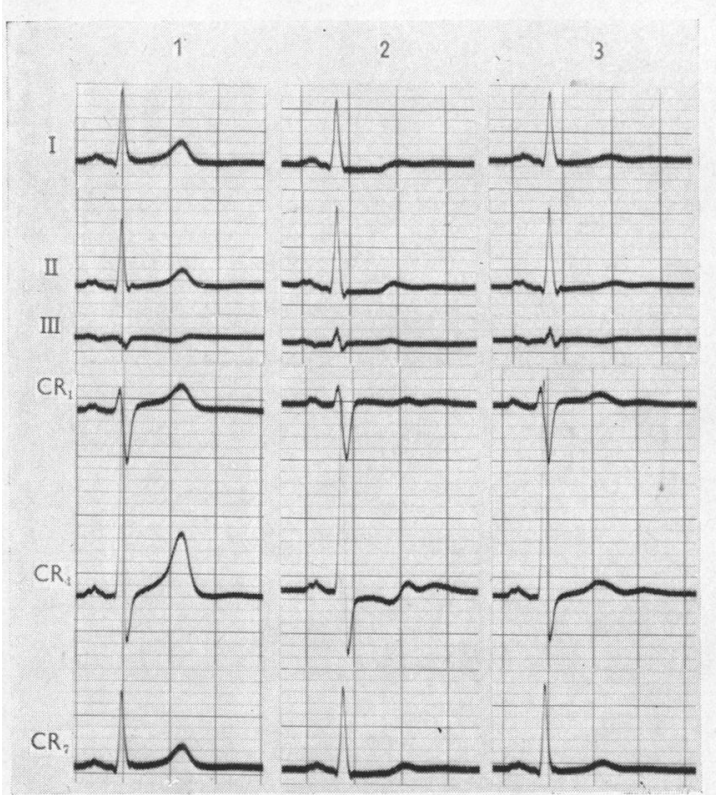

Fig. 1.-The maximum abnormalities of the S-T segments occur in the tracings at two minutes after exercise. This timing is less common; plane or sagging contour of the $\mathrm{S}-\mathrm{T}$ segment is usually more marked in the four-minute tracing. Plane S-T segments in leads I and II with sagging S-T segments in CR1 and CR4 are obvious.

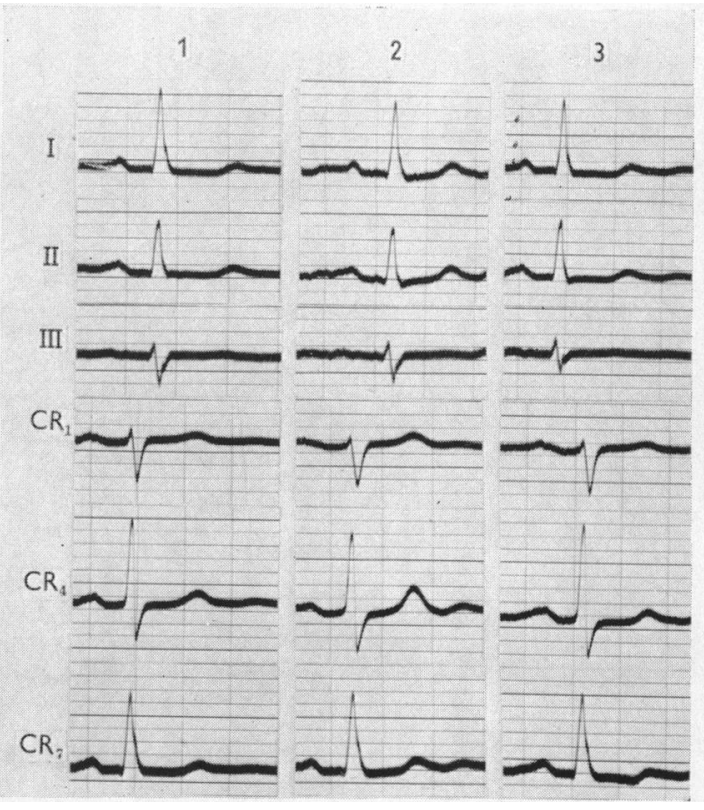

Fig. 2.-The cardiogram before exercise (1) shows abnormalities in the $\mathbf{S}-\mathbf{T}$ segments and in the $T$ waves. In the record taken two minutes after exercise (2) these abnormalities are less marked than before exercise, but they are accentuated in the tracings at four minutes (3).

In all figures, the numbers above the electrocardiograms have the following significance.

$1=$ at rest immediately before exercise.

$2=$ two minutes after completion of exercise.

$3=$ four minutes after completion of exercise.

$4=$ ten minutes after completion of exercise. 
Plane or sagging deformity of the S-T segment was not observed in leads I, II, CR1, CR4, or CR7 recorded after exercise in normal subjects (Lloyd-Thomas, 1960). In that deformities of the S-T segment were observed in lead III in 15 normal subjects after effort, it was decided to disregard these findings in the present study if they occurred in this lead alone. In the present series of 187 patients with classical cardiac pain, the S-T segments showed a plane or sagging deformity after exercise in 155 cases $(83 \%)$, this figure including those in whom an abnormal S-T segment at rest was made more obviously abnormal by exercise. The segment showed a plane deformity only in 44 patients, a sagging deformity only in 55, while in the remaining 56 the S-T showed deformity of the one kind in one or more leads and of the other kind either in other leads or at other intervals. The post-exercise tracings of 32 patients did not show such alterations in the S-T segments. The maximal plane or sagging deformity of the S-T segment was observed at two minutes in 32 (Fig. 1), at four minutes in 141 (Fig. 2), and at ten minutes after completion of exercise in 2 patients (Fig. 3 and 4).

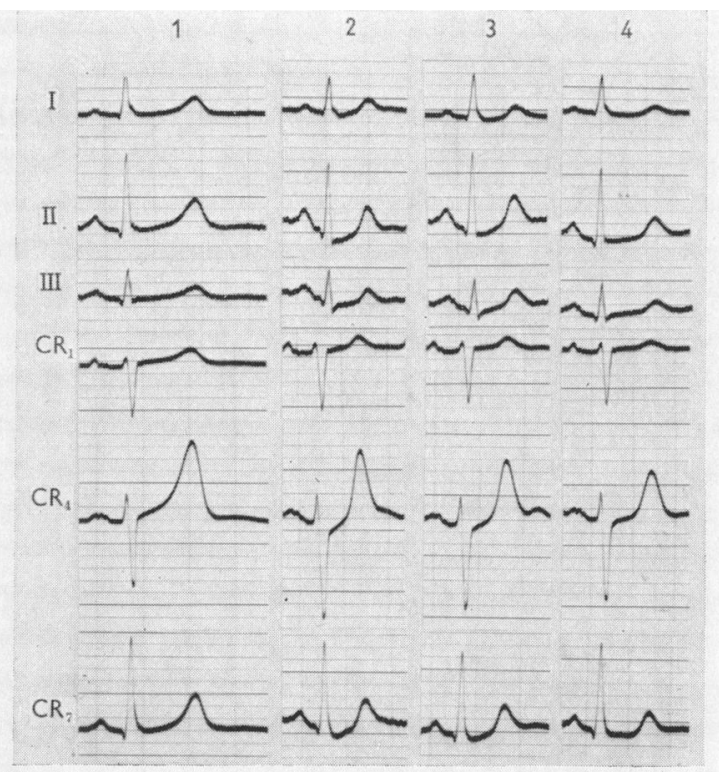

Fig. 3.-1-4 as usual. Depression of the $J$ in excess of one millimetre below the $P-Q$ (or $P-R$ ) segment is present in the record at two minutes. Sagging depression of the S-T segment in lead CR7 occurs only in the tracing recorded ten minutes after the exercise had been completed.

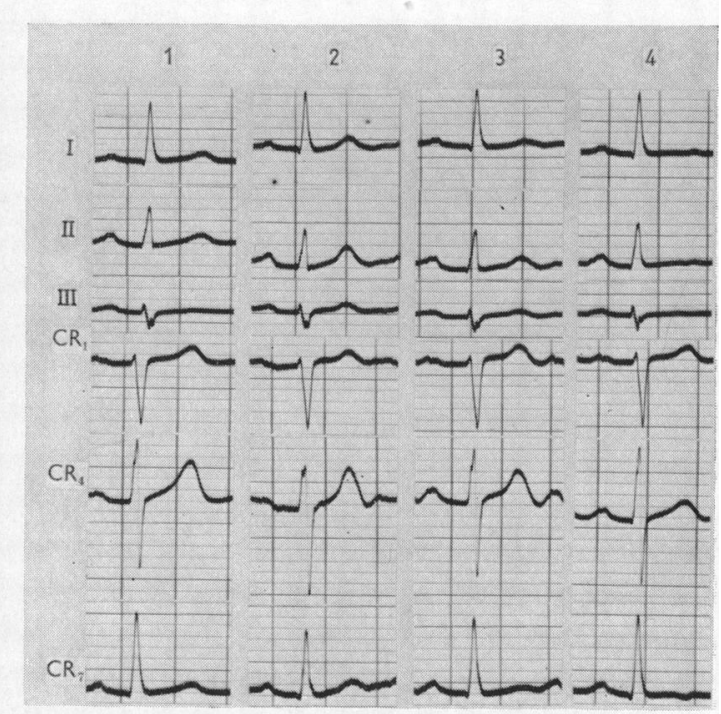

Fig. 4.-1-4 as usual. In the tracing recorded ten minutes after exercise the $\mathrm{S}-\mathrm{T}$ segment is plane in lead I and sagging in lead CR7: these changes were not present in the two tracings recorded earlier.

It is convenient to group together plane and sagging deformities and describe them as ischæmic S-T segments, and to refer to depression of the $J$ of $1 \mathrm{~mm}$. or more below the P-Q segment as significant junctional depression.

The development of ischæmic S-T segments was associated with significant junctional depression in 117 patients. There were 38 in whom ischæmic S-T segments were not associated with significant junctional depression and there were 9 in whom such junctional depression was not accompanied by ischæmic S-T segments. Among the 187 patients there were 119 in whom a total of 264 leads normal at rest showed ischæmic S-T segments after exercise. The development of ischæmic S-T segments need not necessarily occur in the lead that is the most abnormal at rest (Fig. 5).

Thus, in the series of 187 patients, ischæmic S-T segments or significant junctional depression were observed after exercise in $164(88 \%)$, ischæmic S-T segments in $155(83 \%)$, 


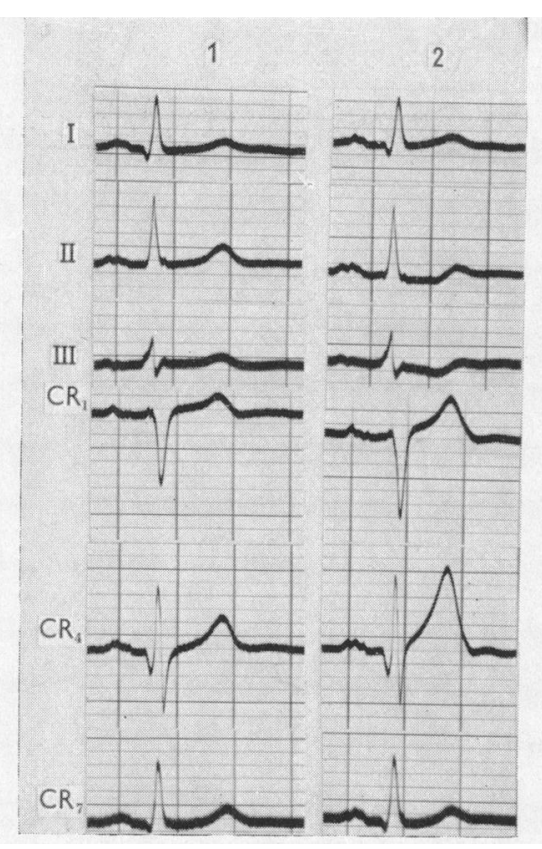

FIG. 5.- The cardiogram at rest shows residual $Q$ wave evidence of anterior cardiac infarction that had occurred twelve months before the exercise test. Sagging depression of the S-T segments occurs in leads II and III after exercise and not in the leads (I and CR4) that are the most abnormal at rest.

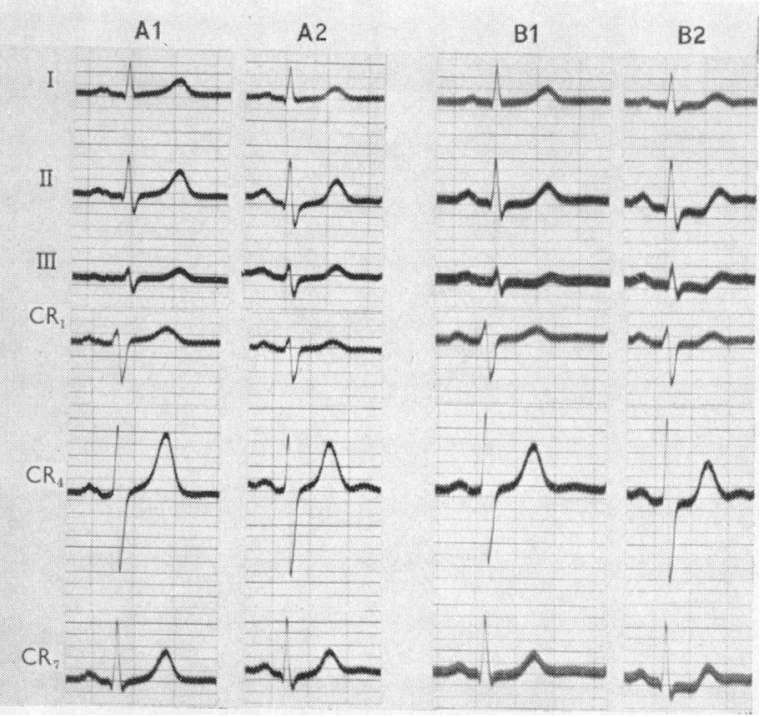

FIG. 6.-Cardiograms from a young healthy subject. No abnormality develops after exercise in the records before the subject was given digitalis (A1 and A2). The effect of digoxin on the cardiogram at rest is seen in B1. After exercise, B2 shows changes in the S-T segments: they are identical with those that occur in undigitalized patient with cardiac pain.

significant depression of the $J$ in $126(67 \%)$, ischæmic S-T segments without significant junctional depression in $38(20 \%)$, and significant junctional depression without ischæmic S-T segments in $9(5 \%)$. There were 12 patients in whom the junctional depression amounted to $3 \mathrm{~mm}$. and in 11 of these the S-T segment showed ischæmic changes. All six with a $4 \mathrm{~mm}$. depression of $J$ showed ischæmic S-T segments.

Most often three or four leads showed either ischæmic S-T segments or significant junctional depression, but the number varied widely. In 5 patients, six leads were affected, in 26 five leads, in 44 four leads, in 49 three leads, in 29 two leads and in 11 only one lead showed the abnormality.

When the post-exercise tracings showed either or both of these changes, lead CR4 or lead CR7 was involved in all but four. Rarely the limb leads alone may show the changes. The changes in the S-T segment were maximal in lead I in nine patients, in lead II in eight, and in either lead CR4, or $\mathrm{CR} 7$ in the remainder.

Great care must be taken to ensure that, at the time of testing, the patient is not on digitalis, as one effect of this drug may be to cause abnormalities in the S-T segments after effort (Fig. 6), even through the tracings at rest show none of the changes expected with this drug or only slight changes as in the example shown.

Elevation of the $S-T$ segment of $1 \mathrm{~mm}$. or more occurred as a temporary phenomenon in 6 of the 187 patients, affecting lead III in three, leads II and III in one, and leads I and CR4 in two patients. In each there was ischæmic depression of the S-T segment in other leads (Fig. 7). 


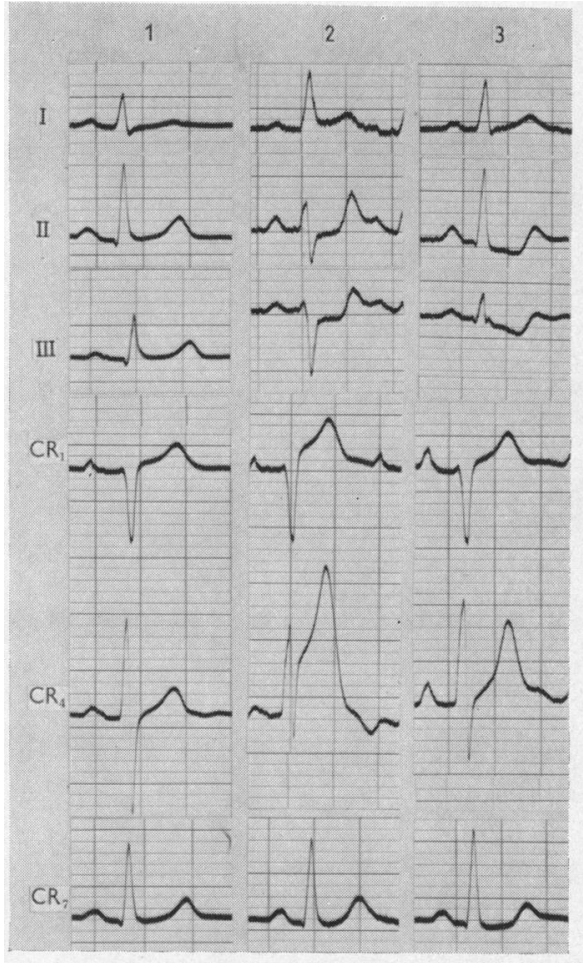

FIG. 7.-The cardiogram at rest shows a low voltage $T$ wave in lead $I$ and an abnormal T wave in lead CR4 (this is obvious if the $T$ wave in lead CR4 is compared with the simultaneously recorded $\mathrm{T}$ wave in lead CR1). An upright $U$ wave follows the abnormal T wave in lead CR4. Great elevation of the S-T segment occurs after exercise particularly in lead CR4 (with inversion of the $U$ wave) and the $T$ wave becomes very tall. At four minutes, sagging contour of the S-T segments appears in leads II and III by which time the pathological elevation of the S-T segments in other leads has disappeared. Deep S waves develop in leads II and III and these disappear in the four-minute tracing producing a transient S2 S3 pattern.

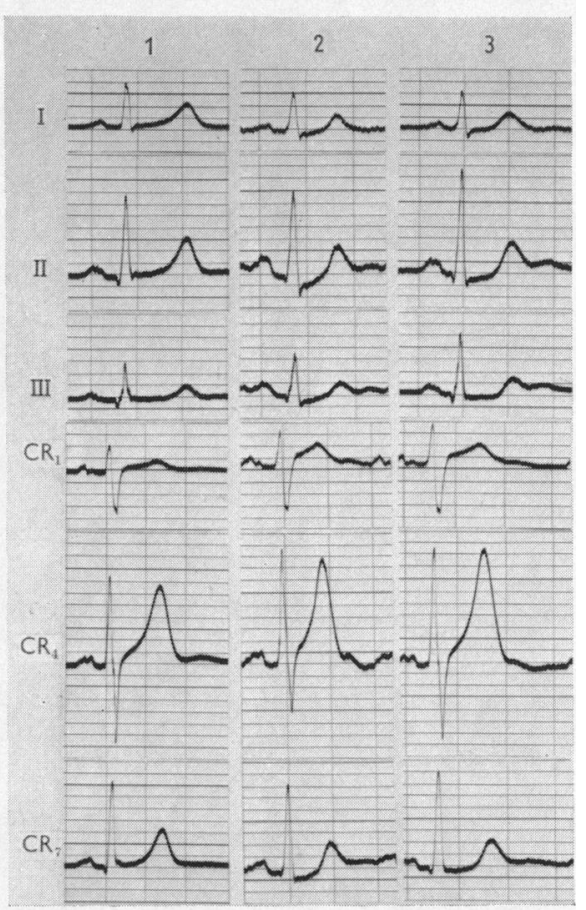

FIG. 8.- In the cardiogram at rest (1) there are small $Q$ waves in leads II, III, and CR7 and there is slight slurring of the QRS complexes in I and CR4. After exercise (2 and 3 ) there is abnormal depression of the $J$ in leads II and CR7. In CR4 the T wave becomes as tall as the $\mathbf{R}$ wave and this is associated with inversion of the $U$ wave in this lead.

\section{$T$ Wave Changes}

In a previous study on healthy subjects, flattening or inversion of an upright $T$ wave was not observed, but changes in the voltage of the wave were common, with the voltage after exercise being reduced to 33-50 per cent of the voltage at rest (Lloyd-Thomas, 1961). Among the 187 patients of this series, flattening or inversion of the $T$ wave in lead I, CR4, or CR7 occurred in nine instances. In each case the S-T segment after exercise developed an ischæmic configuration and the test would have been regarded as abnormal on account of the S-T changes (Fig. 9).

Tall $T$ waves developed after exercise in 5 cases, affecting lead CR4 in each instance: each showed either simultaneous development of ischæmic S-T segments or significant junctional depression in leads II and III (Fig. 8). Pathological inversion of the $T$ wave was present in the tracing taken immediately before exercise in 26 cases. The effect of effort was to correct the 


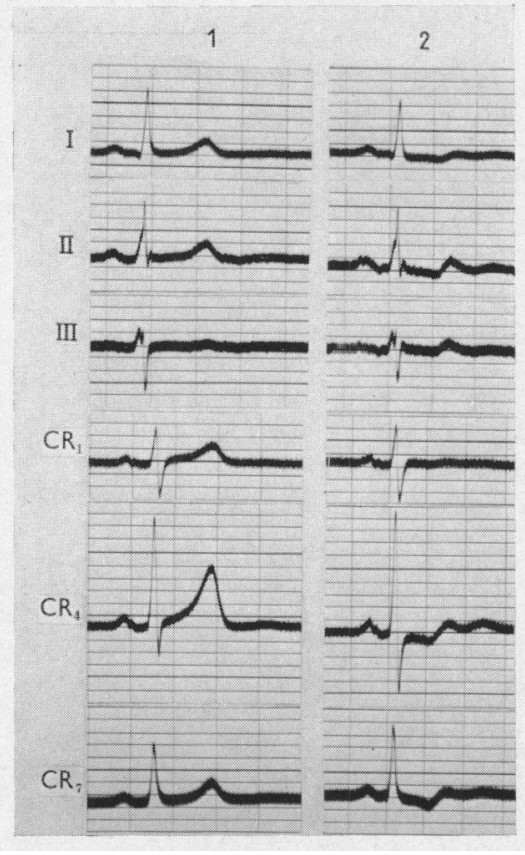

FIG. 9.-The cardiogram before exercise shows slight depression of the T-U segment below the U-P segment in lead II. After exercise the S-T segments develop a sagging contour in all leads, the $T$ waves show decreased voltage particularly in lead I, CR1, CR4, and CR7 and the $U$ waves become more prominent.

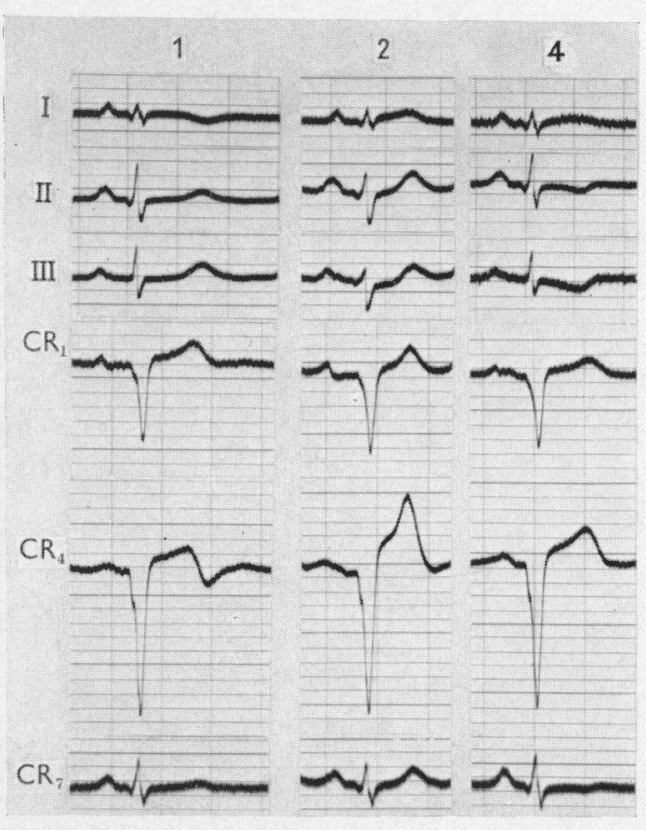

Fig. 10.-1, 2, and 4 as usual. The cardiogram at rest (1) shows abnormalities due to anterolateral cardiac infarction with a biphasic $T$ wave in CR4 and an inverted $T$ wave in lead $I$ in addition to the pathological $Q$ waves. After exercise ( 2 and 4$)$ the $T$ waves become upright in these leads but the $\mathrm{S}-\mathrm{T}$ segments fail to show an abnormal contour until the ten-minute tracing (4) at which time the segments have a sagging contour in leads II, III, and CR7.

inversion in 14 cases, accompanied by abnormal changes in the S-T segments in 13 of them (Fig. 10 and 11), affecting the lead with the inverted wave in some and different leads in others. An abnormally low voltage of the $\mathrm{T}$ wave sometimes became normal after exercise, without simultaneous abnormality of the S-T segment (Fig. 2) or with accompanying abnormality of the S-T segment (Fig. 12).

Inversion of the $U$ wave after exercise was observed in 5 of 187 cases. In each of these there were abnormalities in the S-T segment also (Fig. 7 and 13).

Depression of the $T-U$ segment after exercise developed in 8 of the 187 cases. In five it was accompanied by abnormal changes in the S-T segment, but in three it was the only abnormal finding. On account of the tachycardia, the level of the T-U segment has to be related to that of the P-Q segment (Fig. 14).

Dwarfing of the $R$ wave in lead CR4 so that the voltage of the wave after exercise was less than 60 per cent of the voltage at rest occurred in 9 of the 187 cases. In eight of these, there was an associated ischæmic deformity of the $\mathrm{S}-\mathrm{T}$ segment. In the ninth there was no abnormality of the S-T segments after exercise (Fig. 15). At a later date, however, this patient sustained cardiac infarction and the QRS complex in lead CR4 then closely resembled the complex in the same lead in the post-exercise tracing (Fig. 15A). None of the 67 healthy subjects previously tested showed such a reduction of the $\mathrm{R}$ wave (Lloyd-Thomas, 1960).

The Occurrence of Ectopic Beats, other Arrhythmias, or Conduction Defects. Ectopic beats of ventricular origin occurred in 7 of 67 healthy subjects (Lloyd-Thomas, 1961) after exercise. Of the 


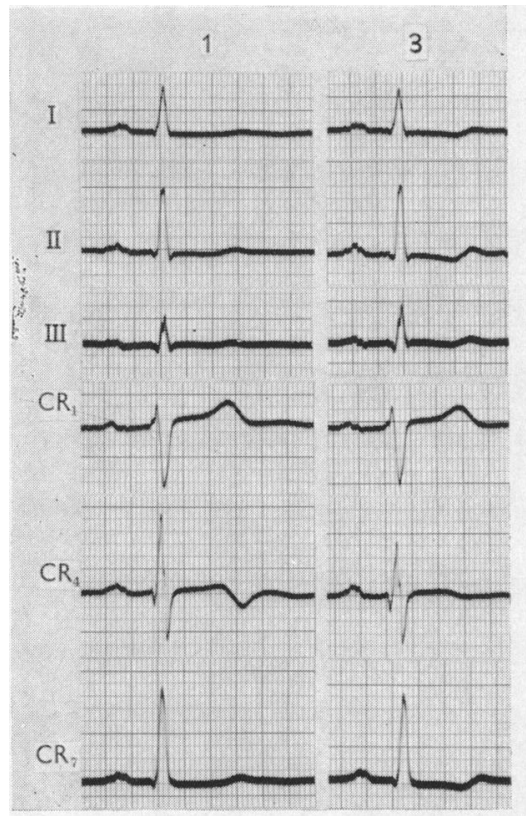

FIG. 11.-The inversion of the $T$ wave in lead CR4 at rest (1) virtually disappears after exercise (3) without the development of ischæmic depression of the $S-T$ segment in the same lead. The $\mathrm{S}-\mathrm{T}$ segments in leads I, II, III, and CR7 become more abnormal after exercise and show a sagging depression.

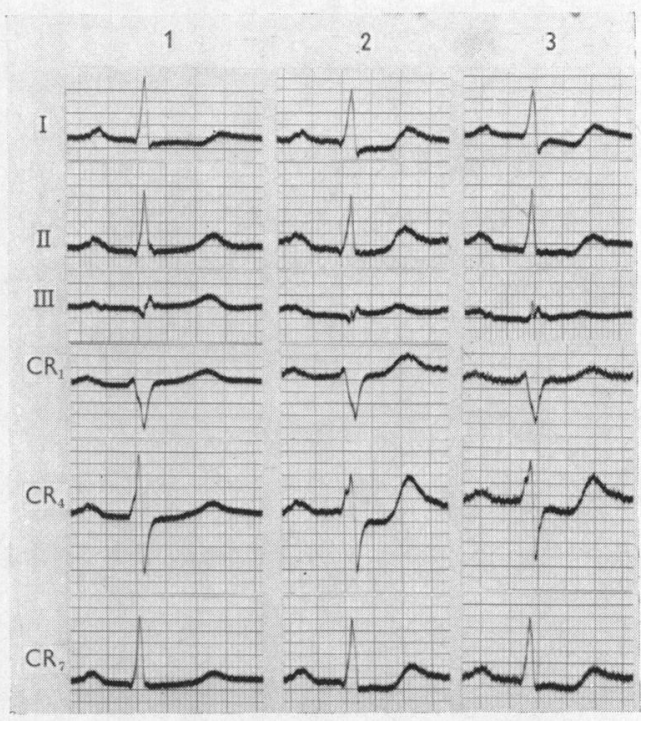

FIG. 12.-Pathological changes in the S-T segments in leads $I$ and $C R 7$ and of the $T$ waves in leads I, CR4 and CR7 are present. The T wave in lead CR4 shows normal voltage after exercice but there is pathological depression of the S-T segment simultaneously, and this is more abnormal at four minutes (3) than it is at two minutes (2). Depression of the $J$ is greater at two minutes.

present series, 21 cases showed ventricular ectopic beats and in 20 of these there were abnormalities of the S-T segment in the post-exercise tracings.

Apart from one patient who developed transient ventricular fibrillation (Fig. 16) from which he recovered spontaneously without ill-effect, no other arrhythmias occurred. None of the patients developed bundle-branch block after exercise.

Elevation of the $P-R$ segment. Experimental studies have shown that damage of the atrial muscle may cause deviation of the P-R segment (Abramson, 1938). None of the patients now reported showed elevation of the P-R segment in the presence of an upright $P$ wave nor depression of the segment in the presence of an inverted $P$ wave, although one patient suffered transient atrial fibrillation and a prolonged attack of cardiac pain within three months of the exercise test.

The Incidence of Pain during the Exercise Test. Pain at the time of testing occurred in 139 of the 187 patients $(75 \%)$. The cardiogram after exercise was considered to be abnormal in 95 per cent of those who developed pain at the time of the test, and in 72 per cent of those free of pain at the time of testing. Gross changes in the tracings may be unaccompanied by any sign of pain (Fig. 18). When the tracing after exercise showed ischæmic S-T segments or significant junctional depression in one lead only, pain occurred in 6 of 13 cases $(46 \%)$ but when five leads were affected pain occurred in 25 of 29 cases or 86 per cent.

Absence of Abnormal Response to Exercise in the Presence of Coronary Arterial Disease. In the present series of 187 patients with classical cardiac pain, 20 did not show an ischæmic deformity of the S-T segment, significant junctional depression, or depression of the T-U segment after exercise (Fig. 17). One showed dwarfing of the $R$ wave in lead CR4. Pain on effort was a symptom common 


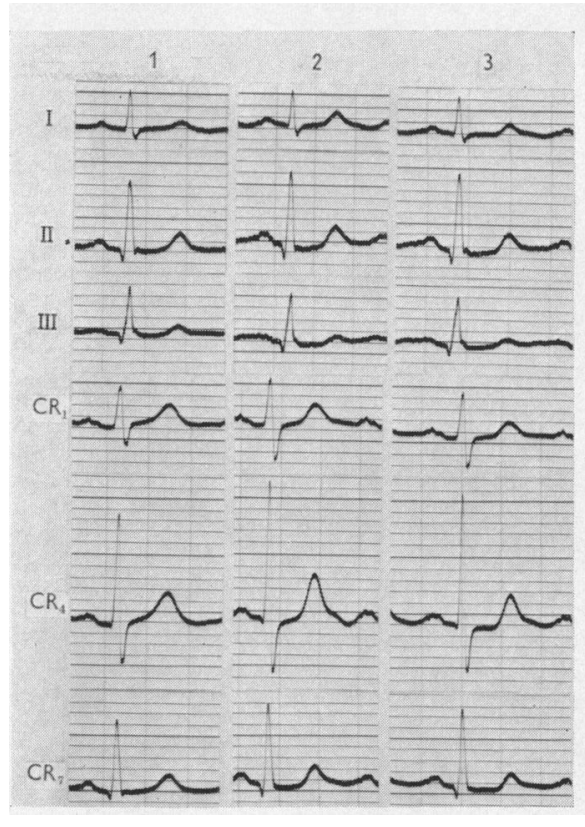

FIG. 13.-Inversion of the $U$ wave in lead CR4 is the most obvious change in the tracing two minutes after exercise (2). The S-T segments in leads I, CR4, and CR7 develop an abnormal contour when four minutes have elapsed (3), the inversion of the $U$ wave in lead CR4 having become less.

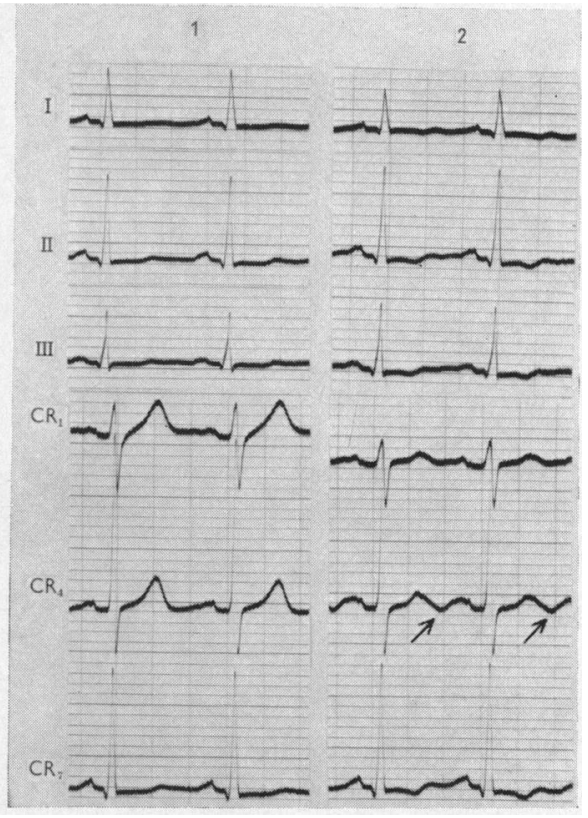

FIG. 14.-The cardiogram at rest shows abnormal $\mathrm{S}-\mathrm{T}$ segments and abnormal $\mathrm{T}$ waves in the limb leads and in lead CR7 (1). Two minutes after exercise (2) the $\mathrm{S}-\mathrm{T}$ segments in these leads develop a sagging contour. Depression'of the T-U portion of the tracing (indicated by the arrows) below the level of the P-R segment occurs in lead CR4 with a normal $\mathrm{S}-\mathrm{T}$ segment in this lead.

to all these patients and a prolonged attack of pain had occurred in 17 of them. Six developed pain at the time of testing. All had shown an abnormal cardiogram at rest at some point during their period of observation. In ten there had been either abnormal $\mathrm{Q}$ waves or abnormal inversion of the T wave (Fig. 19) or both these changes (Fig. 20). The changes in the other 10 patients were of the lesser kind as described by Evans and McRae (1952) and Evans and Pillay (1957).

\section{Discussion}

The importance of alterations in the S-T segment in the diagnosis of myocardial ischæmia has impressed most authors on this subject. The first problem concerns the significance of junctional depression, and the second the importance of the shape of the complete S-T segment. The limits of junctional depression allowed in healthy subjects by those authors who relate the $J$ to the atrial T wave are $0.75 \mathrm{~mm}$. in any lead (Levan, 1945), or $1.0 \mathrm{~mm}$. in any lead (Wood, 1956; Klakeg, 1955; Manning, 1957), but Holzman (1952) and Rosen and Garberg (1957) found that depression of the $J$ might be as much as $2.0 \mathrm{~mm}$. in chest leads with tall $\mathrm{R}$ waves recorded over the cardiac apex and still be normal if the S-T segment followed an ascending course. The abnormal patterns are summarized diagrammatically in Fig. 21.

Many authors have commented on the kind of shape or design of the complete S-T segment that occurs in patients with coronary disease but is not seen in healthy subjects. In 1939 Puddu described a change in the angle between the $\mathrm{S}-\mathrm{T}$ segment and the ascending limb of the $\mathrm{T}$ wave after exercise 


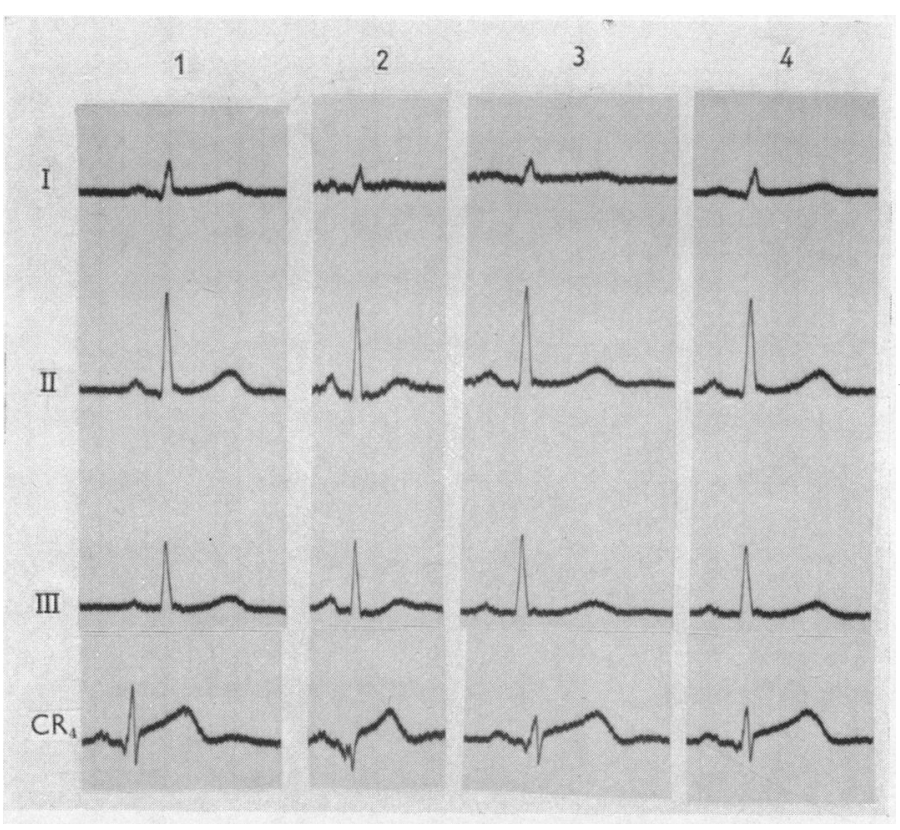

Fig. 15.-1-4 as usual. In the record two minutes after exercise there is great loss of voltage of the $R$ wave in lead CR4. (A) Cardiogram at rest of the same subject recorded six months later after an episode of cardiac infarction. Lead CR4 at rest now shows QRS changes similar to those that had previously occurred after exercise.

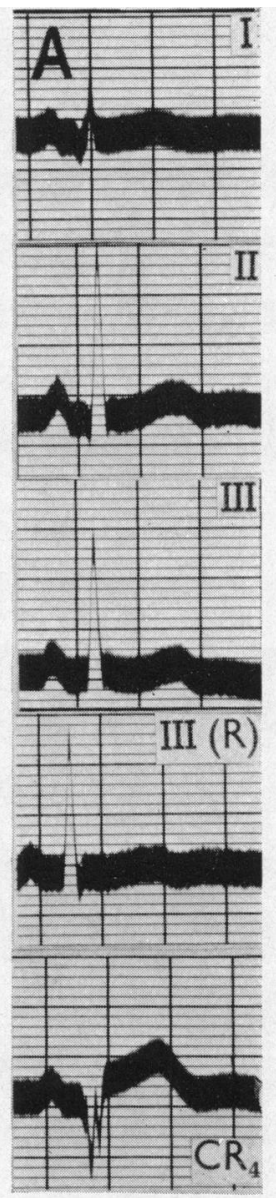

in patients with coronary disease. Twiss and Sokolow (1942) regarded a flattening of the S-T segment as very important and they found it in many of their patients with angina pectoris even though the degree of S-T depression was not abnormal. Wood et al. (1950) never found sagging S-T segments in normal subjects and observed that flat depression of the $\mathrm{S}-\mathrm{T}$ segment was unusual and rarely exceeded $0.25 \mathrm{~mm}$. Myers and Talmers (1955) and Goldman (1956) agreed with Wood et al. (1950) that in healthy subjects the $\mathrm{S}-\mathrm{T}$ segment slopes upwards from the depressed junction to the $\mathrm{T}$ wave. It is thus distinguishable from the plane or wing depression seen in abnormal responses to exercise (Evans, 1956). Holzman (1952) emphasized that the peculiar shape of the S-T segment must be regarded as more important than the absolute degree of depression. Simonson and Keys (1956) were unable to reproduce the typical post-exercise ischæmic pattern of the S-T segment in healthy young men and they therefore regarded it as qualitatively distinct. In this respect it is essential that two or preferably three complexes recorded on a steady base line are available for the assessment of the S-T segment. A wandering base line may occasionally distort the S-T segment giving to it an abnormal appearance and thereby leading to the possibility of misinterpretation. A further possible source of error is the inclusion in measurement of the duration of a plane S-T segment of a portion of the QRS complex that is iso-electric (Lloyd-Thomas, 1960).

In an extensive follow-up study of the Master two-step test with its restricted amount of exercise, Robb et al. (1956) found the death rate from coronary disease was 49 per 1000 for the group who showed an ischæmic contour of the S-T segment: this was more than double that in the group showing 


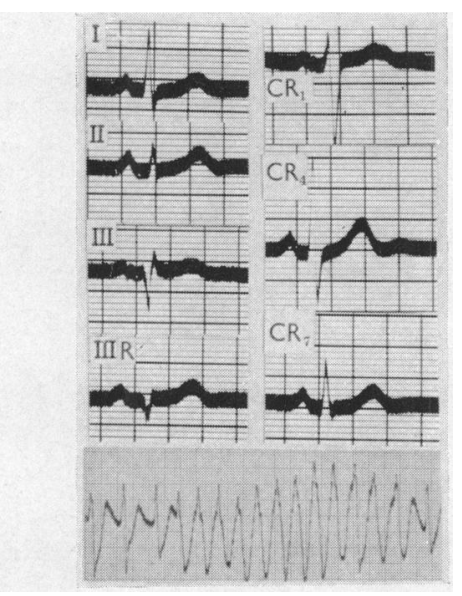

Fig. 16.-Transient ventricular fibrillation developed and this was accompanied by a brief period of unconsciousness. Full recovery occurred. The electrocardiogram eighteen months later showed S-T depression in lead I, the patient leading an active life and having only occasional cardiac pain on effort.

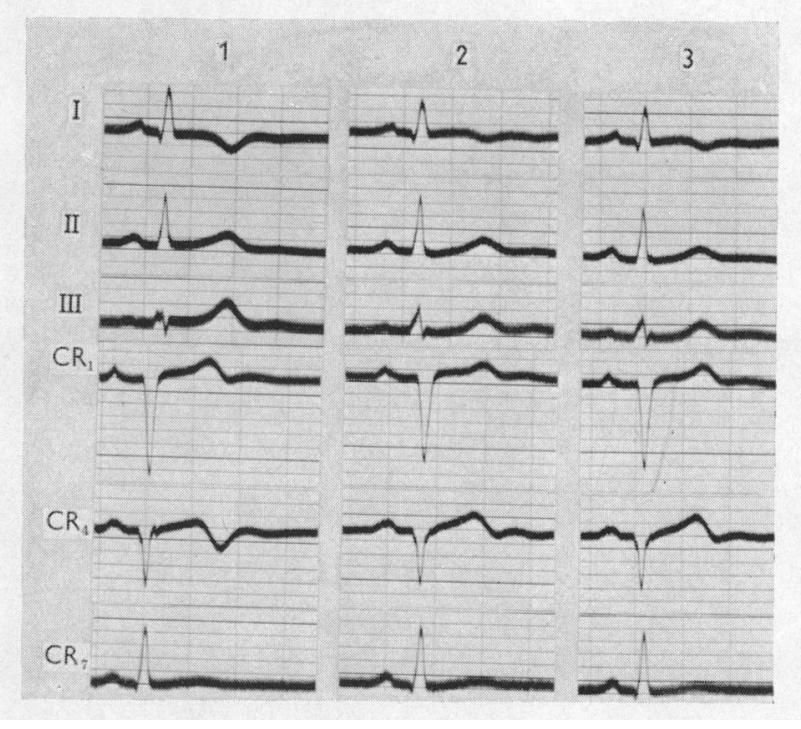

Fig. 17.-1, 2, and 3 as usual. The cardiogram at rest (1) shows anterior cardiac infarction. Neither abnormal depression of the $J$, nor ischæmic depression of the S-T segment occur after exercise ( 2 and 3$)$. The $T$ wave becomes upright in lead CR4.

junctional depression only and about ten times the rate of 5 per 1000 in the group without an abnormal response to exercise. It is important to observe that both the mortality rate and the rate of subsequent coronary occlusion in the group with junctional depression only was higher than would have been expected if junctional depression were a normal response to effort. They found that the mortality rate from coronary disease in patients with chest pain who showed abnormal S-T segments after exercise was independent of the character of the electrocardiogram at rest, being virtually identical for those where it was abnormal and those where it was normal at rest.

In a study involving direct epicardial exploration at the time of operation in 15 patients with coronary disease causing severe cardiac pain, Prinzmetal et al. (1959) found multiple areas of significant depression of the S-T segments over all surfaces of both ventricles, and they attributed the absence of reciprocal elevations to the diffuse distribution of these areas. They could find elevation of the S-T segment only in areas of old myocardial infraction or in areas injured by sepration of adhesions. Epicardial electrocardiograms in dogs made hypotensive by bleeding also showed areas of S-T depression over all surfaces of both ventricles and these could not be distinguished visually from the intervening areas of myocardium with normal electrical activity. In experiments in which a single large coronary artery was occluded, epicardial cyanosis occurred and it was in this area that elevation of the S-T segment occurred.

The clinical and experimental observations suggest that, in those patients in whom widespread S-T depression occurs, the attacks of pain are due to diffuse ischæmia involving both ventricles, whereas in those patients in whom cardiac pain is accompanied by elevation and reciprocal depression of the S-T segments, the ischæmic process involves a discrete area supplied by a single major 


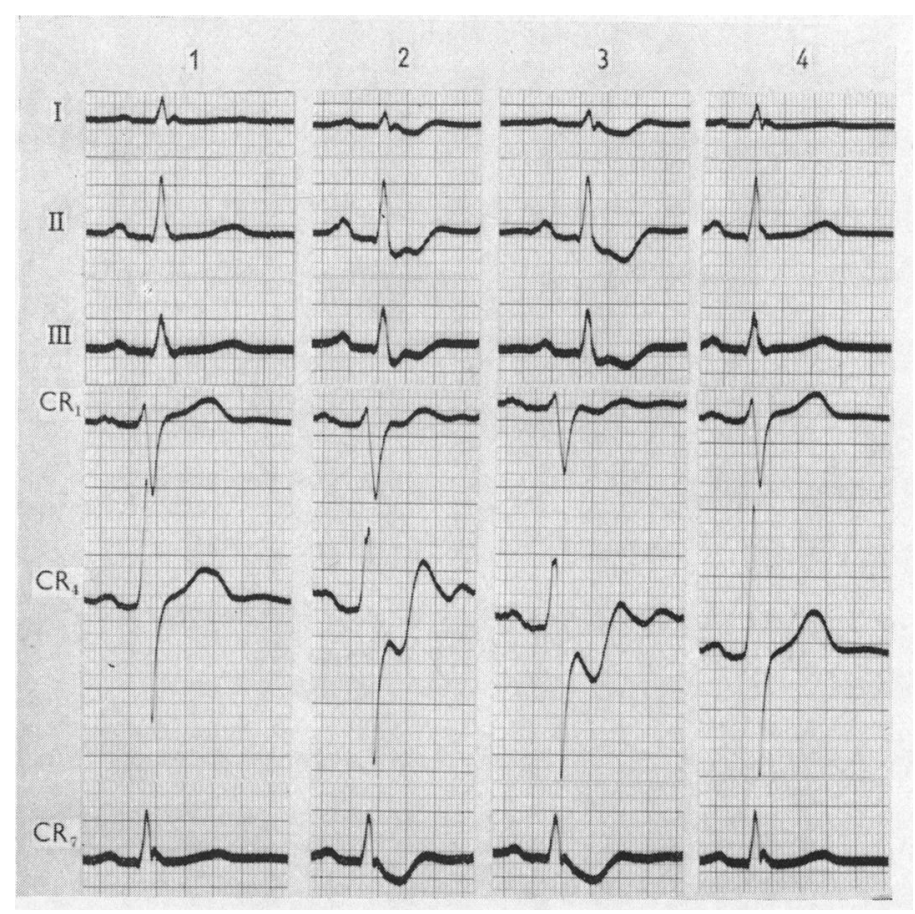

Fig. 18.-The cardiogram before exercise (1) shows abnormal $\mathrm{T}$ waves and notching of the QRS complex. Very great depression of the $\mathrm{S}-\mathrm{T}$ segment with both sagging contour and depression of the $J(2-4)$ occurred in the complete absence of pain at the time of testing. The patient is still active and free of effort pain three years later.

coronary artery or one of its larger branches. The usual finding that S-T elevation occurs in one or two leads only is to be contrasted with the much greater frequency of involvement of many leads in those cases showing ischæmic $\mathrm{S}-\mathrm{T}$ segments.

Although many authors have considered inversion of the $\mathrm{T}$ wave after exercise as abnormal (Whitten and Herndon, 1938; Schott, 1939; Master, 1942; Biörck, 1946; Twiss and Sokolow, 1942; Levan, 1945; Mazer and Reisinger, 1944; Grossman et al., 1949; Yu et al., 1951; Wood et al., 1950; Holzman, 1952; Goldman, 1956; Marriot, 1957), other investigators have more recently established that inversion of the $\mathrm{T}$ wave after exercise may occur in healthy subjects (Goldberger, 1953; Manning, 1957; Rosen and Gardberg, 1957). Master (1957) has revised his earlier view that pathological significance was to be attached to inversion of the $T$ wave induced by effort. In the series they reported in 1956, Robb et al. found that the mortality rate from coronary occlusion in the group of patients showing $\mathrm{T}$ wave changes only (including inversion of a previously upright $\mathrm{T}$ wave) was not significantly greater than in the group with normal exercise tests; and the same conclusion was reached when a comparison was made of the rates of subsequent non-fatal coronary occlusion in the two groups. Simple hyperventilation has been found to produce inversion of the T wave in left chest leads in 37 of 350 healthy subjects (Wasserburger et al., 1956) and this effect could be prevented by the prior administration of potassium salts.

The development of increased voltage of the $T$ wave may be the result of subendocardial injury (Hellerstein, 1948). Smith (1918) found that the $T$ waves became very tall immediately after ligation of the left coronary artery. One patient observed by $\mathrm{Yu}$ et al. (1950) to develop tall T waves after exercise sustained a cardiac infarction ten days later. 


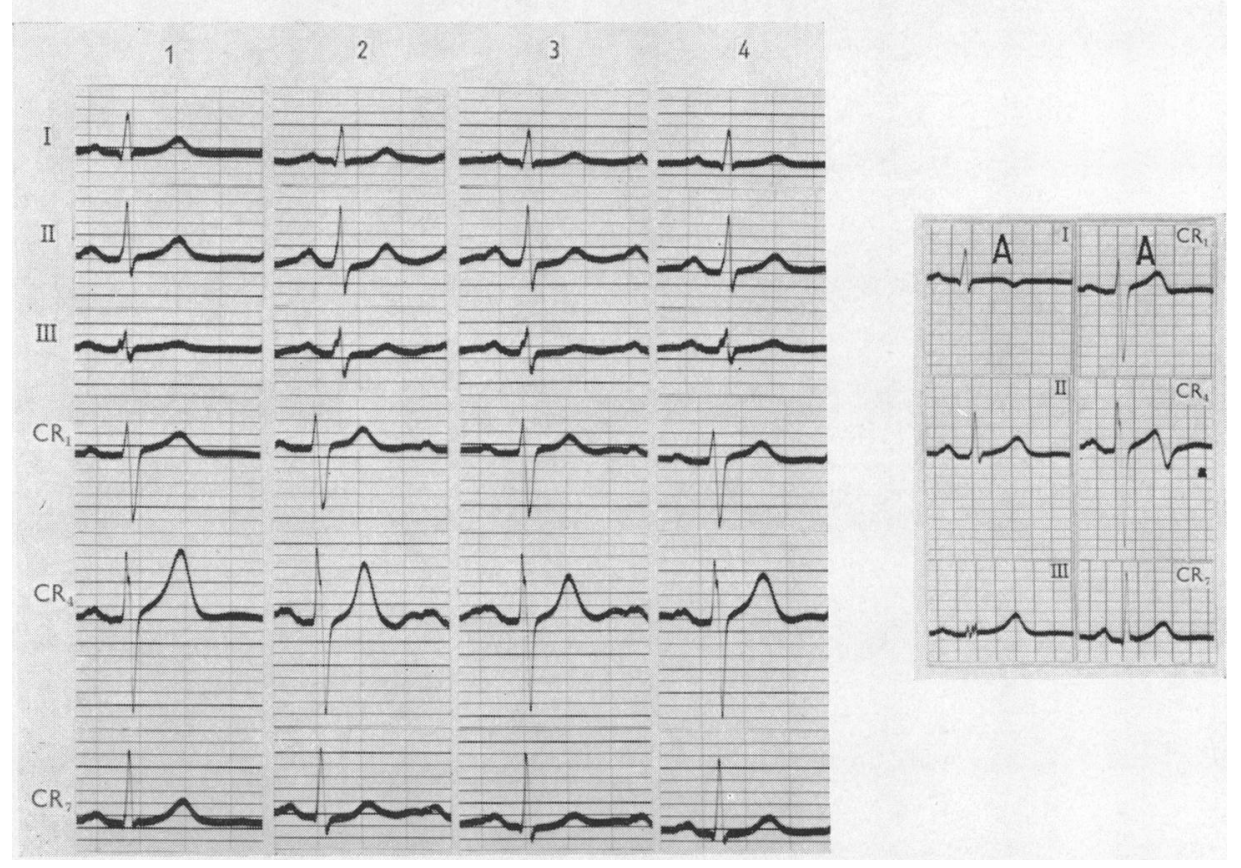

FIG. 19.-1-4 as usual. No abnormality develops in the S-T segments after exercise in this patient with indisputable cardiac pain. The appearance of $T-U$ depression in lead CR4 at two minutes (2) is due to a slightly unsteady base line and was not present in other complexes. (A) Cardiogram at rest, recorded one year before the exercise test, showing pathological changes in leads I and CR4.

The development of an inverted $U$ wave after exercise is regarded as pathological (Palmer, 1948). It is usually accompanied by other abnormalities (Wood et al., 1950; Papp, 1957). Holzman (1950) recorded one patient with coronary arterial disease in whom inversion of the $U$ wave after exercise was the solitary abnormality. Depression of the $\mathrm{T}-\mathrm{U}$ segment at rest in patients with cardiac pain was described by Evans and Pillay (1957). Such a depression as an effect of exercise has not been previously described.

It was suggested by Levan (1945) that dwarfing of the $\mathrm{R}$ wave after exercise, which occurred in one of his cases, might be abnormal. Prinzmetal et al. (1959) described cases in whom the $\mathrm{R}$ wave may disappear during severe attacks of anginal pain.

In a recent clinico-cardiographic analysis, Davies and Evans (1960) investigated the significance of the S2 S3 pattern in which the amplitude of the S wave in leads II and III exceeds that of the R wave in the absence of an $S$ wave in lead $I$ : they found that this distinctive pattern indicated a fault in the antero-lateral aspect of the left ventricle, the myocardial lesion being usually, but not always, an area of cardiac infarction. The myocardial lesion in patients with cardiomyopathy causing fibrosis in the appropriate region may also bring about this pattern, but neither muscular hypertrophy alone nor alteration of heart posture in emphysema or obesity cause it. It is of interest that the pattern described by Davies and Evans (1960) in the tracing at rest may also be brought out by exercise and show then as a purely transient phenomenon (Fig. 7).

The occurrence of transient arrhythmias or conduction defects has more recently been considered to have little diagnostic value (Master, 1957; Robb et al., 1956). The absence of any strict parallelism between abnormal tracings produced by effort and the development of pain at the time is well-known (Scherf and Schaffer, 1952). Riseman et al. (1940) who recorded tracings continu- 


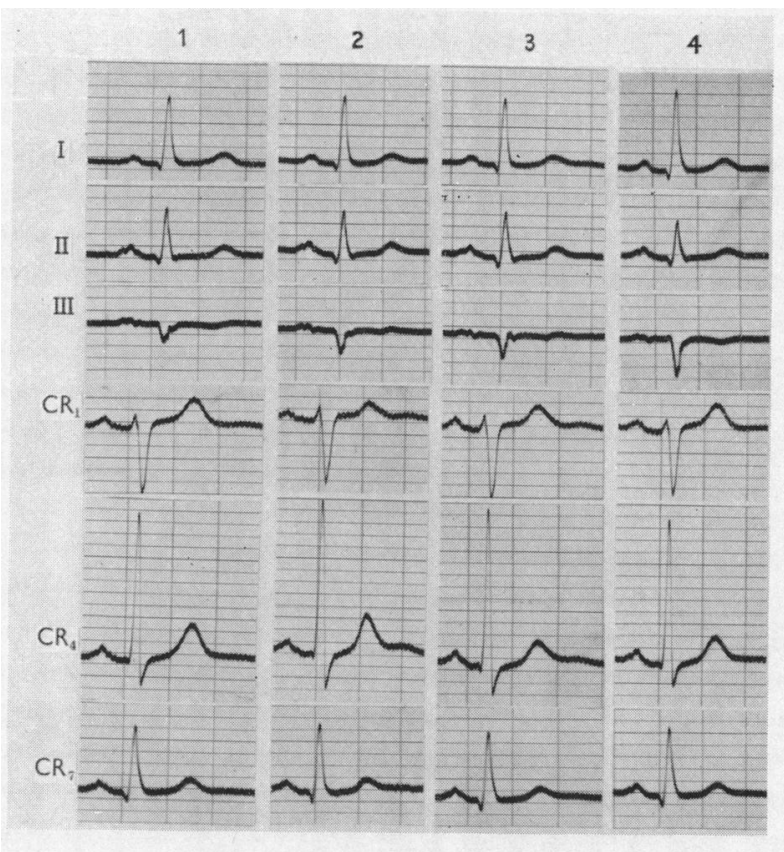

FIG. 20.-1-4 as usual. The cardiogram at rest (1) shows abnormal Q waves in leads II, III, and CR7. After exercise, no additional abnormalities develop, the $\mathrm{S}-\mathrm{T}$ segment retaining its physiological design. (A) Cardiogram at rest recorded one year earlier than the exercise test, showing changes of recent postero-lateral cardiac infarction.

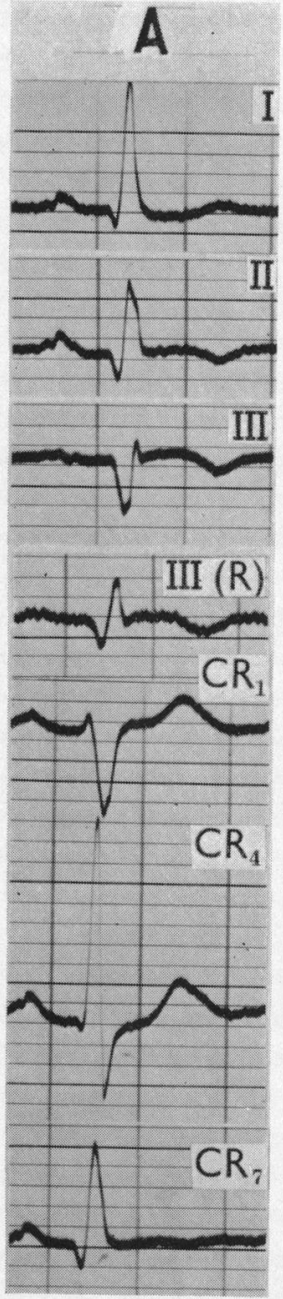

ously during exercise were able to show that abnormal changes might occur after 15-20 trips, whereas pain might not develop until 60-70 trips had been made. Some patients, however, developed pain first and cardiographic changes later. Wood et al. (1950) found that positive exercise tests occurred as frequently when there was no pain at the time of testing as when there was.

The exercise test may fail to show significant abnormalities in the undeniable presence of coronary arterial disease. Master (1957) reported eight patients with coronary disease with cardiographic proof in whom the exercise test was negative. Biörck (1946), Master (1950), and Holzman (1952) observed that patients with positive tests may gradually cease to demonstrate the abnormal features after exercise and eventually lose their abnormal cardiographic response to exercise. This may be attributed to the eventual abolition of ischæmic muscle consequent upon the reorganization and development of collateral vessels or to the reduction of the total mass of ischæmic muscle to such small proportions that the cardiographic exploration usually used is insufficiently sensitive to detect its presence even though cardiac pain on effort may persist.

The studies of Blumgart et al. (1940) and of Lowe (1941) on pathological specimens and the work of Burchell (1940) on experimental coronary occlusion show that a main coronary artery can be occluded without any detectable effect on the myocardium; and that, if the occlusive process occurs 


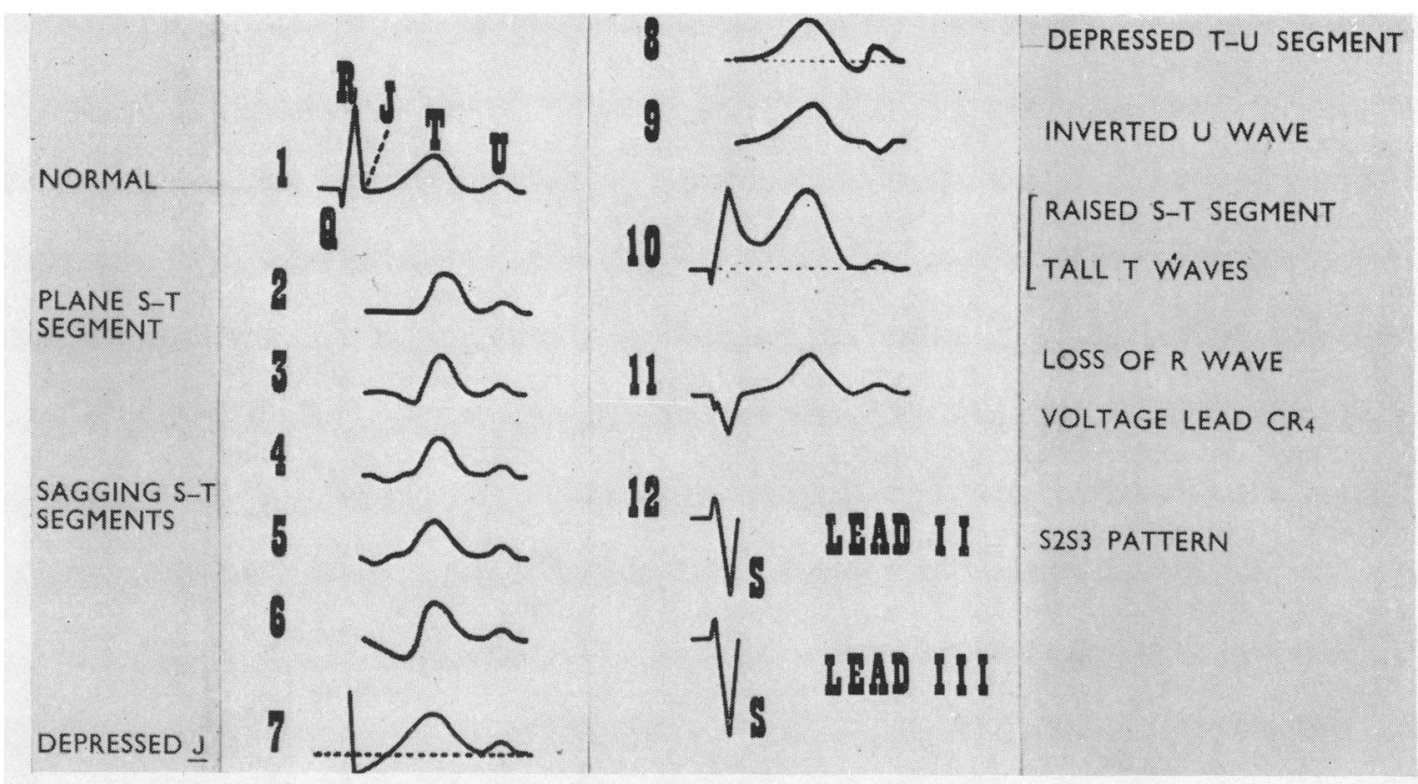

FIG. 21.-Diagrammatic representation of abnormal electrocardiographic patterns that may occur after exercise (2-12). A normal tracing is shown for reference in (1). Abnormalities of the S-T segment are shown in 2-6. (2) shows an S-T segment which is plane for a measured $0.1 \mathrm{sec}$. (or longer). Sagging deformities of the S-T segment affecting the terminal, middle or proximal portions of the segment or the entire segment are seen in $3,4,5$, and 6. Depression of the $J$ is illustrated in 7 (see text for degree of depression that is abnormal). Depression of the T-U segment is the feature of 8 and inversion of the $U$ wave of 9 . Elevation of the $S-T$ segment (exceeding $1 \mathrm{~mm}$.) may be associated with the development of tall $\mathrm{T}$ waves as seen in 10 or these features may occur independently. Loss of the R wave in lead CR4 and development of the S2S3 pattern are represented in 11 and 12 respectively. More than one abnormal pattern may occur in a particular case.

slowly enough, three main coronary vessels may be completely occluded without production of an area of infarction. These experimental and morbid anatomical observations and the finding of a normal electrocardiographic response to exercise offer confirmation of the suggestion that the surviving myocardium in a patient with undoubted coronary arterial disease may in fact be adequately supplied with blood as a result of efficient reorganization of the coronary circulation. In such circumstances a positive test may later return after further branches become occluded and reduce either total or regional coronary blood flow.

In order to explain the later return of a normal electrocardiogram at rest and of a physiological cardiographic response to exercise in patients with cardiac pain showing an abnormal tracing with inversion of the T waves mainly in leads I and in CR1 to CR4 in the absence both of depression of the S-T segment and of abnormal Q waves, Evans (1955) postulated the existence of coronary arteriospasm, affecting the left coronary artery distal to its circumflex branch, as the main operative factor. Such an explanation may perhaps apply to the case illustrated in Fig. 19. Alternatively in this particular instance it may be that there had been slow development of a stenosing lesion in the anterior descending branch, allowing sufficient time for a formation of a collateral circulation that becomes totally adequate, after a transient period of inadequacy represented by the attack of pain and the accompanying temporary cardiographic abnormalities.

\section{SUMMARY AND CONCLUSIONS}

The exercise electrocardiogram was recorded in 187 patients, each of whom gave a history of classical cardiac pain and had shown an abnormal record at rest. The patients were carefully selected 
so as to include only those who were used to considerable physical activity in their daily routine. The exercise was continued until the subject developed pain, fatigue, or breathlessness. Pain occurred in 139 patients.

An electrocardiogram was first recorded at rest and provided this did not show any deterioration when compared with recent records it was followed by exercise with three tracings at intervals of two, four, and ten minutes after completion of effort.

Attention was paid to changes in the $J$, to changes in the design of the S-T segment, to elevation of the $\mathrm{S}-\mathrm{T}$ segment, to the $\mathrm{T}$ wave, $\mathrm{U}$ wave, and $\mathrm{T}-\mathrm{U}$ segment, to reduction in the voltage of the $\mathrm{R}$ wave in lead CR4, and to the occurrence of ectopic beats or other arrhythmias and conduction defects.

Ideally the results of the exercise test should be correlated with the state of the coronary circulation at the time of the test. Since this is not practicable, it has been necessary to evaluate the response to exercise in terms of the assessment of the coronary state of the tested subjects achieved by clinical means and by serial tracings.

Evidence has been obtained to show that the most valid indication of myocardial ischæmia at the time of exercise or shortly after is the S-T segment that shows a plane (i.e. a segment which is flat for a measured $0.1 \mathrm{sec}$. or longer) or sagging deformity (i.e. a segment that at some interval during its course shows a decline from the level of the $J$ ). It is important to be aware that the development of this change may be delayed and only become apparent in records made more than four minutes after the exercise has been completed. Junctional depression of $1 \mathrm{~mm}$. or more below the $\mathrm{P}-\mathrm{Q}$ segment has been shown to occur less frequently than the deformity of the S-T described, and to be absent in many leads showing severe S-T segment deformity.

Other changes may occur after exercise-depression of the T-U segment, inversion of the $U$ wave, dwarfing of the $R$ wave in lead CR4, elevation of the S-T segment, development of tall $T$ waves and of the S2S3 pattern-changes that are not seen in healthy subjects, but have in most instances been accompanied by ischæmic deformities of the S-T segment. These abnormal patterns have been summarized diagrammatically in Fig. 21

The exercise test is a valuable additional diagnostic procedure: it may uncover abnormalities that might be missed without it; it leaves fewer cases to be diagnosed on clinical judgement alone; it may offer evidence to confirm the abnormality of a cardiogram that at rest shows only borderline changes; it may be used to confirm the abnormality of the lesser signs in the resting cardiogram in cases where their recognition is difficult or unconvincing; and it may give an indication of the physiological efficiency of an expanded coronary collateral circulation.

A normal response to exercise does not, and would not be expected to exclude, the presence of disease in the coronary arterial system. It is essential to recognize clearly that what is being tested is the adequacy of coronary blood flow in relation to the metabolic demands of the heart muscle cells at the time of investigation, the balance between supply and demand being interpreted in terms of the recorded electrical activity of these cells.

It is a great pleasure to acknowledge the help and encouragement that I have received from Dr. William Evans and Dr. Wallace Brigden. I would also like to thank Mr. William Dicks and Miss Pamela Whitford for their technical help.

\section{REFERENCES}

Abramson, D. I., Fenichel, N. M., and Shookoff, C. (1938). Amer. Heart J., 15, 471.

Biörck, G. (1946). Brit. Heart J., 8, 17

Blumgart, H. L., Schlesinger, M. J., and Davies, D. (1940). Amer. Heart J., 19, 1

Burchell, H. B. (1940). Arch. intern. Med., 65, 240.

Davies, H., and Evans, W. (1960). Brit. Heart J., 22, 551.

Evans, W. (1955). Brit. Heart J., 17, 15.

- (1956). Cardiology. Butterworth \& Co., London.

- , and McRae, C. (1952). Brit. Heart J., 14, 429.

—, and Pillay, R. K. (1957). Brit. Heart J., 19, 366. 
Goldberger, E. (1953). Unipolar Lead Electrocardiography and Vectorcardiography. H. Kimpton (London).

Goldman, M. J. (1956). Principles of Clinical Electrocardiography. Lange Medical Publications, Los Altos, California.

Grossman, M., Weinstein, W. W., and Katz, L. N. (1949). Ann. intern. Med., 30, 387.

Hellerstein, H. K., and Katz, L. N. (1948). Amer. Heart J., 36, 184.

Holzman, M. (1952). Clinical Electrocardiography (translated by D. Robertson). Staples Press, London.

Klakeg, C. H., Pruitt, R. D., and Burchell, H. B. (1955). Amer. Heart J., 49, 614.

Levan, J. B. (1945). War Medicine, 7, 353.

Lloyd-Thomas, H. G. (1961). Brit. Heart J., 23, 260.

Lowe, T. E. (1941). Amer. Heart J., 21, 326.

Manning, G. W. (1957). Amer. Heart J., 54, 823.

Marriott, H. J. L. (1957). Practical Electrocardiography. Baillière, Tindall and Cox, London.

Master, A. M. (1950). Ann. intern. Med., 32, 842.

—, Field, L. E., and Donoso, E. (1957). New York J. Med., 57, 1051.

, Friedman, R., and Dack, S. (1942). Amer. Heart J., 24, 777

Mazer, M., and Reisinger, J. A. (1944). Ann. intern. Med., 21, 645.

Myers, G. B., and Talmers, F. N. (1955). Ann. intern. Med., 43, 361.

Palmer, J. H. (1948). Bit. Heart J., 10, 247.

Papp, C. (1957). Circulation, 15, 105.

Prinzmetal, M., Goldman, A., Shubin, H., Bor, N., and Wada, T. (1959). Amer. Heart J., 57, 530.

Puddu, V. (1937). Arch. ges Physiol., 238, 467.

Riseman, J. E. F., Waller, J. V., and Brown, M. G. (1940). Amer. Heart J., 19, 683.

Robb, G. P., Marks, H. H., and Mattingley, T. W. (1956). Trans. Ass. Life Insurance Med. Direct. Amer., 40, 52.

Rosen, I. L., and Gardberg, M. (1957). Amer. Heart J., 53, 494.

Scherf, D., and Schaffer, A. I. (1952). Amer. Heart J., 43, 927.

Schott, A. (1939). Guy's Hosp. Rep., 89, 347.

Simonson, E., and Keys, A. (1956). Amer. Heart J., 52, 83.

Smith, F. M. (1918). Arch. intern. Med., 22, 8.

Twiss, A., and Sokolow, M. (1942). Amer. Heart J., 23, 498.

Wasserberger, R. H., Siebecker, K. L., and Lewis, W. C. (1956). Circulation, 13, 850.

Whitten, M. B., and Herndon, J. H. Unpublished data-refer to Missal, M.E. (1938-39). Ann. intern. Med., 11, 2018.

Wood, P. (1956). Diseases of the Heart and Circulation. Eyre and Spottiswoode, London.

, McGregor, M., Magidson, O., and Whittaker, W. (1950). Brit. Heart J., 12, 363.

Yu, P. N. G., Bruce, R. A., Lovejoy, F. W., and McDowell, M. E. (1951). Circulation, 3, 368. 